\title{
Princípios para um \\ Processo Colaborativo
}

\section{* Rafael Ary}

\section{Resumo}

Este artigo trata do reconhecimento de matrizes de trabalho percebidas em diversos processos de criação nomeados como colaborativos, empreendidos por coletivos teatrais com inclinação para a pesquisa de linguagem. Trata ainda da compreensão das estruturas procedimentais comuns ao termo.

Palavras-chave: teatro - processo criativo dramaturgia

\begin{abstract}
This article is about the working matrices perceived in various creative processes named as collaborative, performed by theater collectives with a vocation for language research. This article aims to comprehend the common collaborative process procedures.
\end{abstract}

keywords: theater - creative process dramaturgy

* Doutor em Artes da Cena pela Universidade de Campinas (UNICAMP), dramaturgo, diretor e ator. E-mail: rafaelary@gmail.com 
É importante ressaltar que nenhum dos dois reclama para si a "invenção" do termo, já que a noção de criação em coletivo é secular para o teatro. Está presente em relatos de processos criativos de diversos nomes importantes da história do teatro mundial, como Shakespeare, Molière, Brecht, entre outros. Essa noção de processo criativo compartilhado é secular quando se trata do teatro popular, logo, não se trata de inovação, mas de reatualização de práticas.

A noção de criação em coletivo é inseparável da noção de teatro. Mesmo em épocas nas quais determinados sujeitos imbuídos de suas funções criativas fazem preponderar uma instância criativa sobre as outras no direcionamento do trabalho em teatro - como aconteceu, por exemplo, no Brasil, na chamada de década do encenador (1980) -, o fator coletividade se apresenta a despeito do desejo de qualquer envolvido. Se fôssemos capazes de extinguir qualquer aspecto coletivo de um processo de criação em teatro, pensemos apenas como um exercício de abstração, estaríamos, então, próximos da borda do próprio conceito que caracteriza o que seria teatro. Arte convergente, por unir diversas outras artes a serviço de sua criação, e coletiva em diversos sentidos. Em seu processo de criação e em sua necessidade do grande outro, o chamado público.

Araújo e Abreu, realizaram, ao conceitualizar o processo colaborativo, uma organização formal de ideias dispersas que já estavam sendo praticadas por alguns coletivos de teatro, desde do fim da década de 1970 e durante a década de 1980. Logo, a ideia de processo colaborativo nasceu de práticas que pediam por uma teorização. E que, na verdade, ainda pedem, motivo de tantas pesquisas sobre assunto, tanto na academia quanto em novos coletivos que escolheram nomear seu modo de trabalho dessa maneira.

O processo colaborativo não é um exercício prático de criação que visa dar conta de uma conceitualização elaborada no campo teórico, pelo contrário, ele responde ao momento histórico e social ao qual pertence, materializa um conceito que já estava sendo posto em prática, mesmo sem um nome específico que o categorizasse. Cada coletivo exerce o processo colaborativo à sua maneira. Antônio Araújo, em sua tese de doutorado, localiza o processo colaborativo no tempo.

\footnotetext{
A expressão processo colaborativo começou a ser usada na segunda metade da década de 90 dentro de um contexto de retomada do movimento de teatro de grupo na cena paulistana. O retorno desta perspectiva grupal, que aparece quase como um contraponto à hegemonia do encenador no teatro brasileiro da década anterior, vai, pouco a pouco, ganhando uma dimensão nacional. Não que os grupos tenham deixado de existir após a década de 70 - entre outros coletivos importantes e atuantes nesse periodo, poderíamos destacar o Grupo Galpão, o Imbuaça, o Ponkã ou ainda o Ói Nóis Aqui Traveiz - mas o forte da produção teatral nacional orbitava em torno dos encenadores. São, desse periodo, montagens importantes de Gerald Thomas, Ulysses Cruz, Bia Lessa, Gabriel Vilella, entre outros (ARAÚJO, 2008, p. 57).
}

O processo colaborativo, como expressão aglutinadora de práticas em teatro, se configura após a criação coletiva da década de 1970 e a década de 1980, denominada como a década do encenador. A criação coletiva é considerada, por alguns autores, como antecedente histórico direto do processo colaborativo.

De certa maneira, o processo colaborativo prioriza dois aspectos que eram considerados opostos entre si - se contrapormos a criação coletiva à década do encenador -, que eram:

- $\quad$ O estímulo à criação em coletivo, com liberdade de proposições entre os envolvidos no trabalho, como era corrente na primeira experiência.

- $\quad$ E a determinação de funções artísticas específicas para cada envolvido, como era primordial na década do encenador.

Desta forma, o processo colaborativo promove uma síntese das experiências realizadas nas duas décadas anteriores ao seu surgimento. Quando fomenta dois aspectos até então distintos e separados por considerações irreconciliáveis.

Atualmente, a quantidade de grupos que afirmam criar em processo colaborativo cresceu de forma exponencial por todo o Brasil, ainda que isso não signifique que estes grupos trabalhem sob um modelo rígido. Diria que estes trabalham sob princípios que norteiam suas práticas, de modo a gerar, com o tempo, uma poética específica de cada coletivo. Como se o processo colaborativo, a partir de seus valores comuns, fosse materializado de forma distinta por cada grupo de teatro.

Num dos primeiros textos escritos sobre processo colaborativo, como afirma Antônio Araújo (2008), o dramaturgo Luís Alberto de Abreu fez suas considerações teóricas sobre o fenômeno. 
(...) um processo de criação que busca a horizontalidade nas relações entre os criadores do espetáculo teatral. Isso significa que busca prescindir de qualquer hierarquia preestabelecida e que feudos e espaços exclusivos no processo de criação são eliminados. Em outras palavras, o palco não é reinado do ator, nem o texto é a arquitetura do espetáculo, nem a geometria cênica é exclusividade do diretor. Todos esses criadores e todos os outros mais colocam experiência, conhecimento e talento a serviço da construção do espetáculo de tal forma que se tornam imprecisos os limites e o alcance da atuação de cada um deles (ABREU, 2003, p. 33).

Abreu considera o processo colaborativo um modo de fazer teatro que se contrapõe a um modelo funcionalista de proceder. No entendimento do dramaturgo, um teatro funcionalista estaria preocupado apenas com o resultado estético da obra. A cada artista é delegado apenas uma parte do processo. $\mathrm{O}$ ator deve se preocupar apenas com sua personagem, sem se intrometer em nenhuma outra função. Os artistas, ao trabalhar dessa maneira, são alienados de uma visão do todo. Para realizar a visão de espetáculo de quem estiver comandando, pode ser utilizado todo e qualquer meio para o fim desejado. Os artistas, em uma produção dessa natureza, são uma peça do maquinário de alguém, seja esse alguém o produtor, o diretor ou o dramaturgo.

Os ensaios são, às vezes, uma incômoda etapa para se chegar ao produto. O processo é claramente um meio, do qual não se espera uma atitude formativa, uma preocupação com a qualidade da experiência vivida pelo artista. Esse tipo de teatro é vinculado, geralmente, a um modelo de mercado que transforma a experiência artística em artigos de consumo, ou seja, são oferecidas obras que podem ser de fácil deglutição, ou montagens dos chamados "clássicos", para os gostos ditos mais refinados.

Não é raro ouvir de um artista que trabalha em grupo de teatro, no qual haja a preocupação com a pesquisa de linguagem, que o processo é tão importante quanto o resultado. Logo, ao reforçar a importância do processo, reforça-se também a importância de cada artista para esse processo. Pois, apesar de os integrantes de um processo colaborativo desempenharem funções artísticas específicas, os mesmos são estimulados a não se restringirem ao seu campo de atuação. Pelo contrário, a despeito das suas especialidades, são requisitados a participar de modo crítico e profícuo dos demais campos, ainda que os responsáveis por cada instância de criação do evento teatral sejam estabelecidos. Cada artista deve entender a obra em sua totalidade, ser parte dela, não se restringindo aos contornos de sua contribuição e de seu papel específico.

O processo colaborativo requer uma conduta de criação profícua e dialógica, por exigir de cada artista, independentemente da função desempenhada, que se empenhe para ajudar os outros companheiros no momento de criação. Logo, criar, mais que um direito, é uma necessidade. Sem esse exercício de direcionar o impulso criativo de cada participante para os diversos campos, o processo pode se tornar, aos poucos, um processo funcionalista disfarçado, no qual o direito de manifestação se torna uma questão de foro íntimo, usado quando for conveniente ao indivíduo. O exercício da criação se torna uma conduta de trabalho que impele o sujeito a ultrapassar os limites de sua função específica. Trabalhar em processo colaborativo exige artistas que possam criar de forma abundante, com entusiasmo e perseverança, ou que estejam dispostos a aprender.

Com o objetivo de enriquecer a discussão, trarei à baila outros pontos de vista a respeito do que seria o processo colaborativo. Pela importância, dado o seu pioneirismo no assunto, começarei com uma citação de Antônio Araújo, que, em sua dissertação de mestrado, descreve o processo colaborativo dessa maneira.

Tal dinâmica, se fôssemos defini-la sucintamente, se constitui numa metodologia de criação em que todos os integrantes, a partir de suas funções artísticas especificas, têm igual espaço propositivo, sem qualquer espécie de hierarquias, produzindo uma obra cuja autoria é compartilhada por todos (ARAÚJO, 2002, p. 122).

É interessante notar a semelhança entre as ideias de Abreu, em seu artigo, e as de Araújo, em sua dissertação. Na passagem acima, Araújo ressalta a horizontalidade entre as funções, dessa forma, o grande protagonista é o processo, porém, posteriormente em sua tese de doutorado, o autor modifica de forma sutil seu entendimento sobre a questão da ausência total de hierarquia.

Hoje, contudo, acreditamos que melhor do que "ausência" de hierarquias, seja mais apropriado pensarmos em hierarquias momentâneas ou flutuantes, localizadas, por algum momento, em um determinado polo de criação (dramaturgia, encenação, interpretação, etc.) para então, no momento seguinte, se mover rumo a outro vértice artístico (ARAÚJO, 2008, p. 56). 
Acredito que a evolução do conceito, como vimos no caso de Araújo, acontece quando há a depuração da experiência, ou seja, a prática recorrente se traduz em uma teoria mais consistente, que demonstra uma aproximação entre a sala de ensaio e as linhas escritas. Este tipo de depuração enriquece a leitura do fenômeno, tornando-o potente como farol para novas experimentações.

O conceito de hierarquias flutuantes provoca um movimento, no que diz respeito à leitura do fenômeno, afastando a ideia de uma teoria estanque. Não haver nenhum tipo de hierarquia entre as funções dá a impressão de uma paisagem morta, sem mobilidade, quase harmônica. E não há harmonia nesse tipo de processo, há fricção e esforço de convergência formal, necessário para a consolidação de uma obra.

Cada etapa no processo de criação exige novos enfrentamentos. Dessa forma, é necessário o deslocamento da hierarquia de um polo de criação para outro. Esse movimento exige de cada artista a capacidade de voltar seu potencial de criação para o polo de dominância momentânea. Essa dinâmica hierárquica é fonte de vida para o processo, pois a diversidade de criadores envolvidos numa mesma instância, multiplicam as possibilidades de materiais gerados. Porém, a diversidade de criadores contribuindo para um mesmo campo engendra uma situação de perigo para a convergência formal do espetáculo, pois a grande quantidade de "opiniões" pode romper a sinergia do trabalho, momento ao qual muitos processos não sobrevivem, por esgotamento das relações internas do grupo.

É importante ressaltar que a dinâmica que rege o desenvolvimento do processo, quando o foco criativo está numa instância, exige especificidade procedimental. Se o polo hierárquico se encontra no vértice da dramaturgia, por exemplo, todas as contribuições das outras funções devem convergir com mais afinco para esta, logo, a exigência de contribuir para a função dramaturgia requer a capacidade de executar tal tarefa, o que se remete ao quanto cada artista domina o amplo espectro do evento teatral.

Esse aspecto é esclarecedor quando observamos o modo de trabalhar em processo colaborativo, pois propor material para a cena é ir além de um direito adquirido de opinar. A necessidade de conhecer como cada vértice criativo procede, as especificidades de cada função, fomenta a compreensão do caráter global da obra, fazendo com que cada um vá além da sua função específica.

A pesquisadora Stela Fischer tem, em sua dissertação de mestrado, um foco historicista. Ao discutir a criação e propagação do teatro de grupo, na década de 1990, a autora traça um panorama rico para o entendimento do contexto no qual está inserido o surgimento da expressão analisada neste artigo.

\footnotetext{
O processo colaborativo é um modelo de criação teatral, baseado em princípios coletivos, que vem sendo difundido por diversas companhias brasileiras a partir dos anos 90. Na sua maioria, as companhias são agentes de expansão cultural, enveredando-se pela pesquisa de linguagens cênicas, com propostas de continuidade de trabalho (FISCHER, 2003, p. 1).
}

De maneira geral, sua conceitualização do processo colaborativo se alinha ao de Araújo e Abreu. Em sua dissertação, defende com afinco a filiação entre o processo colaborativo e a criação coletiva. A autora propõe que, em certos aspectos, não há nenhuma diferença entre os dois movimentos.

O ponto de concordância entre Abreu, Araújo e Fischer é a filiação do processo colaborativo à criação coletiva, este é um ponto pacífico entre os três autores. Há uma perspectiva em Abreu e Araújo de que o processo colaborativo avança em aspectos procedimentais e no cuidado com a dramaturgia, principalmente. Porém, há autores que compreendem o fenômeno de outra maneira. A pesquisadora Rosyane Trotta é uma voz dissonante nesse panorama. Para a autora, a especificidade das funções artísticas demonstra um sinal claro de fragilidade na coesão do coletivo.

\footnotetext{
O processo colaborativo seria, por este motivo, um estágio anterior à criação coletiva, no sentido de que lhe faltaria o entrosamento e a afinidade para gerar um objetivo comum e, principalmente, um texto. O encenador e o dramaturgo preencheriam o vácuo criado pela ausência de uma "cultura de grupo", quando não existem as condições necessárias para gerar um sentido coletivo. Não será por acaso que o processo de criação que conjuga texto e cena, hoje muito frequente, se baseie algumas vezes nos princípios da performance (TROTTA, 2008, p. 64).
}

Há uma crítica severa da autora à diferenciação das funções artísticas no processo colaborativo. A crítica torna-se mais aguda quando se trata da presença do dramaturgo em sala de ensaio. Para Trotta, esta presença determina, por si, os lados opostos nos quais se encontram o processo colaborativo e a criação co- 
letiva. Acompanhando o raciocínio da autora, fica claro que um processo de base coletiva não pode, de fato, acontecer quando as funções artísticas são definidas e passam a ser responsabilidade de determinados sujeitos, mesmo quando se proporciona um ambiente de grande fluidez entre os criadores. A base de uma criação em coletivo, para Trotta, é a prerrogativa de que não se deve determinar papéis claramente e, sim, investir no fortalecimento da noção de criação coletiva real, na qual os aspectos das principais instâncias do evento teatral - dramaturgia, encenação e atuação -, surgem unidas por meio da criação do ator. Ao menor sinal de definição de papéis, o processo começaria a se polarizar em uma função específica e dominante.

Por outro lado, podemos questionar essa ausência de funções quando pensamos em alguns exemplos da chamada criação coletiva. A não definição de funções não impediu que um sujeito concentrasse poder suficiente para determinar os rumos artísticos de um grupo ou se tornar a imagem e semelhança do mesmo, como Judith Malina e Julian Beck, no caso do grupo estadunidense Living Theater, como Paulo Flores, no caso do brasileiro Tribo de Atuadores Ói Nóis Aqui Traveiz, ou como José Celso Martinez Corrêa, no caso do Teatro Oficina.

O processo colaborativo proporciona uma gama de interpretações, tanto sobre seus antecedentes históricos quanto sobre os procedimentos criativos, o que vimos foram algumas das mais representativas visões.

O processo colaborativo está distante de uma uniformidade metodológica, dessa maneira, seria mais adequado pensá-lo como uma espécie de modo de criação teatral que possui princípios comuns identificáveis. Estes princípios impulsionam o coletivo para a concepção de uma obra plural e representativa, para tanto, estimula ao máximo o potencial artístico de cada sujeito envolvido no processo de criação da obra teatral, respeitando suas funções artísticas específicas e, ao mesmo tempo, estimulando a permeabilidade criativa entre todos.

Denomino o processo colaborativo como um modo de trabalho, por entender que não há uma rigidez metodológica contida nas experiências que se realizam sob a égide da expressão. O que há é um escopo de valores que permeiam as práticas de diversos grupos, que daí conformam seus experimentos procedimentais.

Já o caráter plural e representativo da obra se traduz na busca por convergir a multiplicidade de vozes de um coletivo em uma obra potente e significativa para os artistas envolvidos e para o público. O exercício de fomentar uma obra artística que possa dar conta dos anseios de um coletivo é, por si, uma tarefa de grande complexidade, logo, é necessário que o coletivo esteja engajado em uma mesma ideia.

Para tanto, encontrar um tema aglutinador é essencial como fator motivador do processo. Pois, sem eliminar as individualidades, um tema que impulsione os artistas para o mergulho criativo - os torne comprometidos com o todo -, pode ser considerado um tema com grande capacidade de mobilização. Sua riqueza e força reside nas camadas de leitura que este possibilita ao coletivo criador, o que pode resultar em uma obra complexa e instigante para o público.

Para encontrar um tema que tenha potência de trabalho é preciso que o coletivo empreenda um esforço radical de busca. O tema precisa ter um caráter aglutinador de desejos e opiniões. Quanto mais questões levantadas a seu respeito, maiores suas possibilidades de exploração. A etapa de seleção exige dos participantes paciência e bom senso, pois, sem isso, o processo pode seguir dois caminhos, pelo menos:

- $\quad$ Ser, disfarçadamente, a realização coletiva da proposição de um criador apenas - o que, por mais interessante que possa vir a ser, destoa do intuito do processo colaborativo.

- $\quad$ Esgotar-se o processo antes de se chegar a um resultado minimamente satisfatório, no qual a convergência formal é possível de ser apresentada, em virtude de uma definição feita sem o devido rigor.

Ainda sobre o caráter representativo do processo colaborativo, destaco a preocupação com o espectador na feitura da obra, no que tange às questões temáticas e propriamente formais do espetáculo. O tema, que aglutina as ações criativas do espetáculo, deve abranger questões importantes tanto para o chamado pequeno coletivo (os criadores) quanto para o grande coletivo (o público). Perceber temáticas potentes e significativas é papel fundamental dos artistas.

O momento de abertura para o público de uma obra constituída em processo colaborativo não encerra as possibilidades de mudanças no espetáculo. Cada apresentação é um momento de importante reavaliação do processo. Algumas impressões colhidas pelos artistas são, até certo ponto, subjetivas. A percepção do tempo de uma fala, da reação do público à determinada cena, nem sempre são impressões precisas.

Alguns grupos que trabalham em processo colaborativo, como o Teatro da Vertigem, utilizam formulários com perguntas, dados à plateia, como maneira de coletar impressões mais precisas, para que estas contribuam no processo de avaliação do espetáculo. Araújo (2008) denomina esse retorno de feedback, porém, eu prefiro utilizar uma palavra da língua portuguesa, por não enxergar a necessidade explícita do uso da expressão 
em língua inglesa, por mais que, em sua tese, o autor justifique sua escolha.

\begin{abstract}
Em geral utilizamos o termo "feedback" no lugar de "crítica". Por mais que se fale em crítica construtiva ou processual ou criadora, este termo traz ainda, infelizmente, uma conotação negativa de julgamento e valoração. Caber-nosia resgatar o sentido de discernimento da raiz desse termo - o que não é tarefa simples, dada a carga de significação que lhe foi imposta. A palavra feedback, ao contrário, pelo significado presente em sua construção composta, traz a ideia de "alimentar de volta" ou de "retroalimentação". Ser nutrido - e não destruído - pelo comentário do outro, carrega uma conotação positiva e generosa, de partilhamento e cumplicidade (ARAÚJO, 2008. p. 170).
\end{abstract}

A partir da explicação do próprio autor, cheguei à palavra retorno, que não está imbuída desse caráter negativo que foi relacionado à palavra crítica e, ao mesmo tempo, contempla a ideia de retroalimentação. Tornar o retorno do público um procedimento constante, pode funcionar como termômetro da obra, possibilitando mudanças importantes ou mesmo a percepção daquilo que o coletivo não deve mais apresentar.

Muitos grupos que trabalham em processo colaborativo usam o recurso da pré-estreia como procedimento de criação, por julgarem importante um retorno externo antes de começar a temporada. A importância da pré-estreia reside no fato de que o processo de montagem geralmente é longo e restrito aos seus participantes. Logo, esta é uma oportunidade de enxergar a obra por outros ângulos ainda não explorados. O profundo envolvimento com o material levantado pode viciar o olhar do artista. O primeiro momento de exposição da obra pode gerar grandes ganhos ao processo.

Para finalizar, acredito que o grande desafio do processo colaborativo seja equacionar, de forma produtiva, o estímulo à criação em coletivo que, ao mesmo tempo, não descaracterize as funções artísticas que cada um exerce. Por que manter as funções artísticas específicas? Porque o paradoxo que equilibra o fomento à criação em coletivo e a manutenção das funções artísticas específicas gera um processo de forte impacto para os artistas envolvidos e, quase sempre, para o espectador que é convidado a compartilhar da obra. O processo colaborativo equaciona o caráter coletivo de criação e o potencial de quem exerce a função artística específica, para empreender um espetáculo que visa uma resultante estética com grande qualidade.

O impacto de um processo colaborativo na formação dos artistas envolvidos é explicado pelo forte caráter pedagógico imbuído na prática, que está presente em seus procedimentos criativos mais basais e pode ser observado no cotidiano de diversos grupos pelo Brasil. $\mathrm{O}$ artista não cria um produto somente, como diria Abreu, ele está em formação, como artista e como ser humano.

Acredito que não exista apenas uma maneira certa de criar em teatro, diversos caminhos podem gerar resultados potentes. A arte é criação humana por excelência, um impulso de vida artificial, cheio de beleza e significado, como diria Oscar Wilde, no prefácio de seu livro O Retrato de Dorian Gray:

\footnotetext{
"O artista é o criador das coisas belas. Revelar a arte e ocultar o artista é o objetivo da arte. (...) Toda arte é, ao mesmo tempo, superficie e símbolo. Aqueles que vão abaixo da superfície fazem-no por sua conta e risco. Aqueles que leem o símbolo fazem-no por sua conta e risco. É o espectador, e não a vida, o que a arte reflete realmente
} (WILDE, 2004, p. 9-10)."

O modo que se escolhe para proceder artisticamente está intimamente ligado aos valores nos quais se acredita. A criação teatral de uma época reflete valores da sociedade na qual está inserida, tanto em seus conteúdos artísticos quanto em seus modos de criar. Sendo assim, lanço mão das palavras do mestre Luís Alberto de Abreu, que, em sua sabedoria de quem pratica o que acredita, afirma.

\footnotetext{
"Artistas há que transitam por vários processos de criação e grandes obras têm sido criadas de forma solitária por artistas, da mesma forma que resultados mediocres podem ser construídos de forma partilhada entre muitos participantes. Reiteramos que o processo colaborativo não é método de se criar um bom espetáculo. Para isso não existem fórmulas nem métodos e na criação só sabemos como entramos nela e não como dela vamos sair. O que não quer dizer, é evidente, que todos os processos são igualmente bons e igualmente válidos. Um processo está intimamente relacionado ao fim desejado (ABREU, 2003. p. 41)."
} 


\section{Referências}

ABREU, Luís Alberto de. Processo colaborativo: relato e reflexão sobre uma experiência de criação. Cadernos da Escola Livre de Teatro. Santo André, v. 1, n. 0, 2003.

ARAÚJO, Antônio. A gênese da Vertigem: o processo de criação de O Paraíso Perdido. Dissertação de Mestrado em Artes Cênicas. Escola de Comunicações e Artes. Universidade de São Paulo. São Paulo, 2002.

A encenação no coletivo: desterritorializações da função do diretor no processo colaborativo. Tese de Doutorado em Artes Cênicas. Escola de Comunicações e Artes. Universidade de São Paulo. São Paulo, 2008.

FISCHER, Stela. Processo colaborativo: experiências de companhias teatrais brasileiras dos anos 90. Dissertação de Mestrado em Artes. Instituto de Artes. Universidade Estadual de Campinas. Campinas, 2003.

TROTTA, Rosyane. A autoria coletiva no processo de criação teatral. Tese de Doutorado em Teatro. Centro de Letras e Artes. Universidade Federal do Estado do Rio de Janeiro. Rio de Janeiro, 2008.

WILDE, Oscar. O retrato de Dorian Gray. Tradução de Lígia Junqueira. Rio de Janeiro: Civilização Brasileira, 2004. 